\title{
SOME MEDICO-SOCIAL PROBLEMS INVOLVED IN CHILD ADOPTION
}

\author{
BY \\ H. P. TAIT, M.D., F.R.C.P. Ed., D.P.H. \\ Assistant Maternity and Child Welfare Medical Officer, Corporation of Edinburgh
}

In this communication it is proposed to outline some of the commoner problems of both medical and social importance in child adoption and to make some suggestions as to their avoidance or mitigation. The views are put forward in the light of several years of close contact, supervision, and medical care of infants and children, both before and after their adoption either through an adoption society or the local authority.

Social workers have always been puzzled to know why Britain, long noted for her enlightened legislation for the protection of the weak, had nothing on her Statute Book, until very recent years, which had been designed specifically to control child adoption.

\section{History of Ädoption Legislation}

The case of Moses is an early example of child adoption, and ancient Babylonia, China, and the Roman Empire each had their laws to regulate and overcome two major problems in this connexion, viz., the problem of the childless couple desirous of having children, and that of the unwanted child. In the United States of America, the first adoption law was passed in 1851, and the dawn of the present century saw most European countries with legislative machinery for dealing with the adoption of children. In spite of Lady Mary Wortley Montague's lively interest in adoption in the eighteenth century, it only became a matter of Parliamentary concern in Britain in 1920, largely on account of the conditions precipitated by the world war of 1914-18. This agitation, rapidly increasing, culminated in the passing of the Adoption of Children Act on August 4, 1926, based on the recommendations of the Tomlin Committee. This Act applied only to England and Wales, an Act for Scotland being passed on August 1, 1930. As a result of these two Acts, child adoption was, for the first time, put on a proper legal basis in Britain.

The following brief summary covers the main provisions of these two Acts. The Acts enable single persons or a married couple only to adopt a child legally through specified courts. In the case of married couples, the application to adopt must be signed by both spouses. The child to be adopted must be under twenty-one years of age and unmarried, and the adopters not less than twenty-one years older than the child. The natural parents or legal guardians of the child must give free consent to the adoption. After full investigation of all facts relative to an application to adopt a child, the court, if satisfied, grants an Adoption Order authorizing the applicants to adopt that child. - On the granting of an Adoption Order, all legal responsibilities of parent to child and vice versa pass from the natural to the adopting ones, with the exception of inheritance of property. In this case, the child still has the claim, in law, that it would ordinarily have on its natural parents, but it has no claim on the estate of the adopters, unless such claim is expressly stated and designated by name in their wills; the mere terms ' my child' or 'my issue' in a will do not cover an adopted child. The Registrar-General is required by the court to enter the new surname and christian names chosen by the adopters of the child in a special register, the Adopted Children's Register, and a certified copy of this entry may be used in lieu of a birth certificate. No financial transactions must be contracted between natural parents and adopters without the consent of the court.

The Adoption of Childrén (Regulation) Act, 1939. which, owing to the war 1939-45, did not become operative until June 1, 1943, was based on the recommendations of the Horsburgh Committee. Under this Act, all societies dealing with child adoption have to be registered with the local authority. They cannot practise for gain, and their activities are subject to close scrutiny. A probationary period of three months is required after the child has been placed with the prospective adopters, before any application can be made to the court for an Adoption Order. Adequate medical certification of each child is essential, and the society is required to receive back any child unsuitable or unsuitably placed for adoption. - Private individuals who assist in placing children under nine years of age with adopters are required to notify the local authority at least seven days before the transfer of the child to the adopters. The local authority must then arrange for the supervision of the child by its child protection visitors until either an Adoption Order is made or until the child attains the age of nine years. If the 
intending adopters, already having the child in their possession, change their residence, the local authorities of the areas of both existing and future residence must be notified at least seven days before the change of address takes place. Advertisements purporting to deal with child adoption are made illegal.

Such legislation, though not devoid of many loopholes, was long overdue, since, before legalized adoption, children were exposed to the gravest dangers. For example, a child well received into an adopter's household might be claimed later by the mother, sometimes for improper purposes. On the other hand, a child might be disposed of by the mother to an individual who offered her money; and, after that person's whim had been satisfied and the child tired of, it might be returned to the mother or to a charitable institution, frequently in a damaged state, or it might even be re-adopted with a further monetary transaction.

In discussing some of the problems encountered in adoption work; it must be re-emphasized that all the circumstances quoted below were encountered in the routine medical work associated both with an adoption society and a local authority. These problems will be considered under the three headings of : the mother; the adopters; the child. It must be borne in mind that reasonably satisfactory legislation is not in itself a sufficient safeguard unless it is backed up by an intelligent and sympathetic administration.

\section{The Mother}

The mother who wishes to have her child adopted must, on application to the local authority or adoption society, be interviewed. Invariably the child is illegitimate, and the prospects of the mother being able to look after it negligible or absent. The mother's reasons for wishing to have the child adopted must be carefully scrutinized, and every effort made to persuade her to keep her child if her future prospects are reasonably good, or if some arrangements can be arrived at for the care of the child till the mother is in a position to do so herself. Second and subsequent illegitimate children for adoption should be viewed with caution, and only rarely should such cases be accepted.

A careful medical history of the mother is essential, with, naturally, special reference to hereditary disease on either the maternal or paternal sides, if this last is known. If there is any history at all suspicious, there should be no hesitation in rejecting the application forthwith.

A complete medical examination of the mother is very desirable, though legally this is not compulsory. This examination may be carried out during the ante-natal period, or at the time of application for adoption if this is subsequent to the birth of the child. A blood Wassermann and Kahn test should be insisted upon, and with the more widespread application of mass radiography the chest might profitably be examined also.

The social worker who interviews the mother on behalf of the local authority or adoption society must see that the mother appreciates the loss of control of her child should it be adopted, and the mother is required to read and to sign a memorandum stating that she realizes fully the step that she is about to take. A point of paediatric interest might be mentioned here, viz., the folly of allowing a mother who proposes to have her baby adopted to nurse the infant except during the neonatal period, for the maternal tie may become so strong that either she is left a broken, frustrated woman when the infant is taken from her, or else she decides to keep the child for which she can never provide.

\section{The Adopters}

Adopters, on application to the local authority or adoption society, must be interviewed and must give their full reasons for wishing to adopt a child. In most instances the childless state of the prospective adopters is due to medical or surgical reasons. The sole reason for wishing to adopt a child should be love of children, and this cannot be emphasized strongly enough. Great care must be taken to ensure that the proposed adoption is not being tried in an effort to patch up a disintegrating marriage in the hope that the child may remedy a deeper defect. Steps must be taken also to confirm that the adopters appreciate their obligations and duties towards the child, and this, of course, includes reasonable surety of economic security and social responsibility. References from people of standing and integrity, usually in the place of domicile of the adopters, are required. The home of the adopters must be visited by a responsible official, frequently a health visitor experienced in such work, who reports on the medico-social and suitability aspects. There is usually some reluctance to accept the single adopter, though the law permits this to be done. As yet there is,- unfortunately, no legal obligation to obtain a medical certificate of fitness of the prospective adopters. Legislation on this aspect is urgently required, but enlightened local authorities and adoption societies may insist upon this, and may consider no such application unless it is accompanied by a certificate of medical fitness. The prospective adopters' medical adviser would be in a position to furnish a confidential assurance that the family history did not show any hereditary or constitutional disability.

\section{The Child}

In dealing with the child, the paediatrician has a vitally important function to fulfil. Because adoption is a life plan, not just one for babyhood, his judgment must be carefully weighed. On his recommendations depend not only the future happiness of the child, but also that of the adopters, and the passing of a child as fit for adoption cannot be lightly undertaken. All his paediatric knowledge is required if he is to be successful in his recommendations that the child is mentally and physically 
fit for adoption. The examination of the child must be full and complete, and, where possible, the natural parent should be present so that a full medical history (including the obstetric one) may be obtained, and every precaution taken to exclude those children with any suspicious history of hereditary disease or of disease in earlier life which might have left residua. Wassermann and Kahn tests should be carried out in all cases, even as confirmatory to these carried out on the mother's blood.

No child can possibly be passed as fit for adoption as a result of a first examination only. The child must be subjected to frequent observation, and this obtains particularly in respect of mental development, since, as is well known, this follows a fairly well-defined age pattern. Thus, motor, adaptive, language, and personal-social behaviour are subject to observation (Gesell and Ilg, 1943). As most of the children for adoption are infants seen a short time after birth, this observation period is all the more important.

A word might be said about the 'baby home' in which the period of observation is passed. These homes, run in conjunction with adoption societies and suitably supervised, should be small units with modern equipment and a high staff/child ratio, so that the infants may receive the individual mothering and interest which they have lost from the breakingoff of continuity with their mothers. As Gesell remarks, it is too easy to forget that the infant has a psychology, and our methods of care affect the mental as well as the physical welfare of the infant. The routine, impersonal as it may frequently be, the hurried attitude of a harassed and too often inadequate staff such as might be met with in larger homes, does not give the child the chance to progress steadily forward.

The paediatrician's interest in the child does not cease after it has entered the adopters' household, and by his wise advice and supervision he may avert breakdowns between the child and the adopting parents. The adoption situation is new both to the adopters and the child, and the reactions of both to the situation created must be haridled with care and toleration. The advent of the child into the adopters' home in most instances will, after the initial 'labour' pains are over, result in untold happiness to all concerned. Two quotations from recent letters may be of interest as indicating the new atmosphere introduced into the home where the love of children prevails:

'We are indeed lucky. She is just a joy and so healthy and full of energy.'

' Of course we think she is wonderful, and cannot imagine what we did without her. She is very bright and lively and thoroughly enjoys life.'

Advice to adopting parents regarding the selection of a child to adopt is a very difficult problem. Happy indeed are the child and adopters who take to each other at their first meeting. Yet this happens so often that one is constrained to wonder whether the paediatrician should ever exert any direct influence on the prospective adopters in the choice of a child. Where the child has been observed in a baby home for some time, and the adopters are known to the paediatrician, he may offer advice on their choice, but generally it is preferable for him to take a relatively small part in the actual choosing of the child. His co-operation should be restricted chiefly to the medical examination of the child.

The problems which have just been discussed are those which are likely to be encountered in everyday adoption work. No attempt has been made to cover the whole field.

\section{Summary}

Child adoption has been known to occur in civilized countries from early times, but its legal control in Britain was instituted for the first time only in 1926.

The main clauses of the three Adoption Acts in operation in Britain have been briefly quoted.

Some of the commoner medico-social problems met with in adoption practice are considered under the three headings referable to the mother, the adopters, and the child.

I wish to express my thanks to Dr. W. G. Clark, Medical Officer of Heath, and to Dr. T. Y. Finlay, Maternity and Child Welfare Medical Officer, Edinburgh, for their kind help and criticism in the preparation of this paper.

\section{REFERENCE}

Gesell, A., and Ilg, F. L. (1943). Infant and Child in the Culture of Today. London. p. 62. 